University of Zurich

Department of Economics

Working Paper Series

ISSN 1664-7041 (print)

ISSN1664-705X(online)

Working Paper No. 30

\title{
Conspicuous Consumption and Satisfaction
}

\author{
Rainer Winkelmann
}

September 2011 


\title{
Conspicuous Consumption and Satisfaction
}

\author{
RAINER WINKELMANN* \\ University of Zurich, CESifo and IZA
}

August 2011

\begin{abstract}
Traditional tools of welfare economics identify the envy-related welfare loss from conspicuous consumption only under very strong assumptions. Measured income and life satisfaction offers an alternative for estimating such consumption externalities. The approach is developed in the context of luxury car consumption (Ferraris and Porsches) in Switzerland. Results from household panel data and fixed effects panel regressions suggest that the prevalence of luxury cars in the municipality of residence has a negative impact on own income satisfaction.
\end{abstract}

JEL Classification: D12, D62, I31

Keywords: Ferrari, Porsche, status, consumption externality, Swiss Household Panel

\footnotetext{
*Address for correspondence: University of Zurich, Department of Economics, Zuerichbergstr. 14, CH8032 Zurich, Switzerland, email: rainer.winkelmann@econ.uzh.ch. I thank Holger Bonin, Andrew Oswald, Kevin Staub, two anonymous referees and seminar participants in Bayreuth, Bamberg, Glasgow (Annual Meetings of the European Economic Association 2010, Fraser of Allander Institute, 2011) and Lausanne (Workshop in Redistribution and Well-Being) for helpful comments, Oliver Lipps for support in obtaining the data, and Wishiro Keo for excellent research assistance.
} 


\section{Introduction}

There is ample evidence that individual well-being is affected by comparisons with others. Status concerns are an important feature of our social existence. Higher ranked individuals are on average healthier (Wilkinson, 2000, Marmot, 2003) and live longer (Oswald and Rablen, 2008) than lower ranked ones. They also report higher levels of happiness in survey questions (Di Tella at al., 2007). Relatedly, actions of others provide a "frame of reference" for own decisions (Frank, 1991). As Karl Marx (1847) famously noted, "A house may be large or small; as long as the neighboring houses are likewise small, it satisfies all social requirement for a residence. But let there arise next to the little house a palace, and the little house shrinks to a hut."

For the economist, such positional concerns and frame of reference effects are important, as they can lead to inefficient market outcomes. For example, resources spent on improving one's status are wasteful from a societal point of view, as one person's gain is another person's loss. As Layard (1980) puts it "For, though individuals are willing to make sacrifices to improve their individual position, the net result of status-motivated action will be no increase in status satisfaction but an increase in sacrifice." (p. 738). Perhaps the best studied example of such wasteful competition occurs in the presence of relative consumption effects, i.e. if an individual's utility depends not only on the level of her own consumption but also on how that level compares with the consumption of others.

One cause of such interdependence has been explored by Veblen (1899) who, referring to the behavior of the nouveau riche during the Second Industrial Revolution in Britain, coined the term of "conspicuous consumption". He argued that this consumption "is evidence of wealth, and thus becomes honorific, and . . . failure to consume a mark of demerit." Veblen thus singles out consumption that is intently used as a signal for status. More broadly, 
conspicuous consumption refers to any consumption activity that is, first, literally "visible" to outsiders, and, second, positional, in the sense that own consumption utility depends partly on relative rather than absolute consumption.

Despite the obvious interest for microeconomic theory (e.g. Layard, 1980, Dupor and Liu, 2003, Arrow and Dasgupta, 2009), and the widespread reference to the concept in the economic literature, there is surprisingly little direct empirical evidence on the effect of conspicuous consumption on well-being of others. The objective of this paper is to contribute such evidence within the context of the life satisfaction literature, in order to provide direct empirical quantifications of the presence and size of consumption externalities. I propose to use information on what people say when asked whether they have a good and worthwhile life, i.e., survey information on "subjective well-being", "satisfaction", or "happiness", in order to estimate the effect of conspicuous consumption on others' satisfaction, and thus the utility loss due to such consumption. The empirical approach using satisfaction equations is in the spirit of previous papers concerned with the valuation of intangibles, including van Praag and Baarsma (2005) on the cost of airport noise, Luechinger (2009) for air quality and Frey et al. (2009) for terrorism.

This paper focuses on a specific instance of conspicuous consumption, the purchase and display of luxury sports cars in Switzerland. Two brands are considered, Ferrari and Porsche. These are the two main automobile producers present in the Swiss market that specialize in the upper segment of luxury sport cars. The demand for these cars has increased over the recent decade. Whereas total sales of new cars declined between 2001 and 2007, new registrations of Ferraris and Porsches increased by almost 80\% (in 2008, the numbers went down, see Figure 1). The consequence was a doubling in market share of such luxury sports 
cars among all newly registered cars from $0.4 \%$ in 2001 to $0.8 \%$ in 2007.

------ Figure 1 about here -------

The empirical approach in this paper combines information from various sources. Individual level satisfaction (with income and with life in general) and other socio-demographic characteristics (most importantly current household income) are obtained from the 2002 and 2007 waves of the Swiss Household Panel. In a second step, regional information is matched to each person-year observation. The first, obtained from the Federal Roads Office, provides the number of new luxury car registrations (Ferrari and Porsche per 1000 population and year) in the municipality and canton of residence $1^{1}$ The second, obtained from the Federal Tax Administration, includes information on average incomes and income inequality, again for each municipality, canton and year.

The statistical hypothesis being tested is that income and life satisfaction are not related to the local or regional density of new luxury sport cars, ceteris paribus, against the alternative that there is a negative association. The empirical analysis employs linear regression models with fixed individual specific as well as region specific effects.

\section{Background}

\subsection{Modeling conspicuous car consumption}

The following model, an adaptation of Dupor and Liu (2003), provides a useful framework for thinking about conspicuous car consumption. Let $c$ denote own consumption of car attributes (such as horsepower, or looks) and $\bar{c}$ the average attributes in the population of

\footnotetext{
${ }^{1} \mathrm{~A}$ municipality is the smallest administrative and political unit in Switzerland. Depending on size, it can be a village, town or city.
} 
cars. The utility function of identical consumers can be written as

$$
U(c, \bar{c}, x)
$$

where $x$ is a non-conspicuous composite good. Suppose that people enjoy horsepower $\left(\partial U / \partial c=U_{1}>0\right)$ as well as non-conspicuous consumption $\left(\partial U / \partial x=U_{3}>0\right)$, that marginal utility is diminishing $\left(\partial^{2} U / \partial c^{2}<0, \partial^{2} U / \partial x^{2}<0\right)$, and that horsepower consumption is conspicuous and generates envy $\left(\partial U / \partial \bar{c}=U_{2}<0\right)$. People then choose $c$ and $x$ in order to maximize utility subject to the budget constraint

$$
c+p x \leq y^{f}
$$

where $y^{f}$ is income at full employment and leisure is part of $x$. Substituting the constraint into utility function (1), individuals thus maximize

$$
U(c, \bar{c}, g(c))
$$

where $g(c)=\left(y^{f}-c\right) / p$. They take public consumption $\bar{c}$ as given and trade off the marginal utility from own conspicuous consumption with the marginal utility from non-conspicuous consumption. The first-order condition for a maximum is

$$
U_{1}(c, \bar{c}, g(c))+g^{\prime}(c) U_{3}(c, \bar{c}, g(c))=0
$$

or

$$
\frac{1}{p}=\frac{U_{1}(c, \bar{c}, g(c))}{U_{3}(c, \bar{c}, g(c))}
$$

It is a-priori undetermined whether public consumption $\bar{c}$ affects the solution to (3), and hence what the optimal own consumption levels for $c$ and $x$ are. For example, the marginal rate of substitution between conspicuous and non-conspicuous consumption is independent of $\bar{c}$ if the utility function is either additively separable, or multiplicative (e.g. of Cobb-Douglas 
form) in $\bar{c}$. In these cases, envy has no behavioral consequences although it lowers a person's utility. In other cases, consumption comparisons can lead to behavioral responses. Suppose, for example, that an increase in $\bar{c}$ raises the marginal utility of conspicuous consumption relative to that of non-conspicuous consumption. As a consequence, it is optimal to reduce non-conspicuous consumption (including leisure, i.e. work more, for example) and to increase own conspicuous consumption. In such a case, it is in principle possible to infer the presence of a consumption externality from observed behavior. In general, behavioral data cannot prove the absence of envy effects for the stated reasons. Suppose instead that $U(c, \bar{c}, g(c))$ can be measured empirically. Then it becomes possible to determine the effect of $\bar{c}$ on $U$, if any, using statistical methods.

Learning about such envy effects is important from a policy perspective, as they result in an inefficient allocation in general, and "overconsumption" in particular. To see this, note that in a symmetric equilibrium with $c=\bar{c}$, we obtain

$$
U_{1}(c, c, g(c))+g^{\prime}(c) U_{3}(c, c, g(c))=0
$$

This equilibrium is inefficient, since individuals do not account for the negative externality $U_{2}(c, c, g(c))$ they impose on others. The social optimum requires that

$$
U_{1}(c, c, g(c))+U_{2}(c, c, g(c))+g^{\prime}(c) U_{3}(c, c, g(c))=0
$$

Assuming concavity of $U(c, c, g(c))$, the optimal car consumption $c^{*}$ that solves (4) is less than equilibrium consumption, an instance of overconsumption. A government imposing a luxury tax can remove or alleviate this inefficiency.

The underlying assumption of identical consumers is admittedly unrealistic, as every person would then buy cars with similar attributes, whereas in reality Ferraris and Porsches are only bought by few people. Changing the model in order to allow for heterogeneity in 
endowments (whereby "rich" people would have a greater demand for $c$ ) would not change the essential mechanisms leading to overconsumption.

\section{$2.2 \quad$ Empirical literature}

Consumption externalities involve two parties: those who generate them and those who are affected. There are a number of recent empirical studies regarding the first group of people, i.e., the decision of, and demand for, conspicuous consumption. Johannsson-Stenman and Martinsson (2006) study the perceived importance of status concerns in consumption decisions. Charles et al. (2009) show that Blacks and Hispanics devote larger shares of their expenditure bundles to visible goods (clothing, jewelry, and cars) than do Whites with similar incomes. This observation is consistent with a simple consumption model where the demand for conspicuous goods is a function of group income. Heffetz (2011) uses a signalingby-consuming motive to derive and test differential predictions regarding income elasticities of visible and non-visible goods.

In this paper, the focus is instead on the second group of people. Traditionally, economists have analyzed the effects of consumption externalities based on revealed preferences, i.e., by studying changes in behavior. For example, as shown above, an increase in comparison consumption can affect the marginal rate of substitution between consumption of conspicuous and non-conspicuous goods, thereby changing observed choices. Specifically, an increase in reference consumption can lead to an outward shift in labor supply and an increase in own consumption, an effect known as "Keeping up with the Joneses" (Frank, 1999). A well known study along this line is Neumark and Postlewaite (1998) who show that a woman's employment probability increases if the sister's husband's income is greater than the own husband's income. More recently, Kuhn et al. (2011) show that living next to a winner in the Dutch Postcode Lottery increases the level of own car consumption. Even if an externality 
leaves the marginal rate of substitution between conspicuous and non-conspicuous goods unchanged, other margins can be affected, for example, those related to residential choice. Since conspicuous consumption can be interpreted as a negative neighborhood attribute $\bar{c}$, its effect on $U$ can, in principle, be determined using location decisions (or backed out from housing prices using a hedonic regression).

An alternative to the revealed preference approach is the stated preference method. Stated preferences, as elicited in discrete choice experiments (DCE), rely on hypothetical choices. The key advantage of DCEs over revealed preference studies is that it gives the researcher full freedom and control in manipulating relative positions. In particular, it is possible to include the consumption level of others into the choice set (thereby effectively internalizing it). An example of this approach is the "parallel universe" question, where one has to choose between two fictitious societies, for example one, society A, where everyone lives in a house with 3,000 square feet of floor space, and another one, society B, where the own house has 4,000 square feet while neighbors have 5,000 square feet. Frank (1999, 2004) contents that most people prefer society A. Solnick and Hemenway (1998) have conducted more elaborate discrete choice experiments with real populations. Interestingly, they find that leisure appears to be inconspicuous - perhaps in part because it is not so easily observed by others.

The stated preference and the revealed preference approaches both have their weaknesses. The validity of discrete choice experiments critically hinges upon people's cognitive ability in valuing hypothetical alternatives as well as on their truthfulness in responding to such questions. DCEs generate hypothetical choice situations, which may be very far from respondent's actual experiences, and people may decide differently when faced with real choices. The revealed preference approach makes strong assumptions regarding the rationality of agents and the functioning of markets. For example, it is well possible that individuals are 
not aware of all relevant neighborhood attributes when they make their location decision. For long-term residents, transaction costs may prohibit a relocation in the presence of negative consumption externalities, as long as these costs are sufficiently large.

Given the limitations of the stated and revealed preference approaches, I propose to directly estimate the effect of conspicuous consumption on utility, by using stated life- and income satisfaction as a proxy for utility. Recent evidence suggests that satisfaction can be measured with a reasonable degree of reliability, sufficient to be able to compare means over time or across regions, or to use multiple regression analysis to understand the factors that affect individual satisfaction (Krueger and Schkade, 2008). Moreover, satisfaction taps into key components of quality of life. For example, many studies have found a positive correlation between satisfaction, or happiness, and longevity. One of the mechanisms seems to be that satisfaction protects the healthy from becoming sick, by lowering stress, which in turn enhances the immune system (Veenhoven, 2008). Studies have also shown that individuals who report higher levels of satisfaction with their lives are rated as happier by their relatives and friends, tend to smile more during social interactions, have higher prefrontal brain activity (the part of the brain associated with positive states), and are more likely to recall positive life events (Layard, 2005).

There is a sizeable literature on the effect of relative income on satisfaction. Studies using survey data (e.g., Clark and Oswald, 1996, Luttmer, 2005, and Dynan and Ravina, 2007) usually find large negative effects of increased reference incomes ceteris paribus, holding own income constant. This evidence provides an explanation of the so called Easterlin paradox (Easterlin, 1974) whereby large increases in GDP over time have apparently not led to correspondingly large increases in average satisfaction.

While relative income effects may be related to conspicuous consumption, the connection between the two is not obvious. Unfortunately, direct evidence on the effect of relative 
consumption on satisfaction is much more sparse, perhaps due to the absence of appropriate data sets. A notable exception is Hsee et al. (2008) who report on evidence from data collected in 31 large cities in China. Participants were asked about their jewelry possessions and their satisfaction with it. The researchers found that residents of cities with more expensive jewelry were not any happier on average about their jewelry than residents of cities with less expensive jewelry (although within each city, people who owned more expensive jewelry reported greater satisfaction with their jewelry).

Hsee et al. (2008) note that while some consumption experiences (such as ambient temperature, having social company etc.) are inherently evaluable and often have a natural scale, others (the size of a diamond, the horsepower of a car) are not, and hence are much more prone to social comparisons. Of course, comparison effects can also relate to past own consumption. There is evidence that hedonic adaptation plays a major role in some consumption activities, such as the size of a house or apartment, but not in others, such as the duration of a commute (Stutzer and Frey, 2008). One factor contributing to the speed of adaptation is uncertainty: unstable or uncertain consumption experiences create longer lasting happiness than their stable and certain equivalents (Kahneman and Thaler, 1991).

\section{Data}

The empirical analysis of this paper combines data from a number of sources: information on individual satisfaction and household income is obtained from the Swiss Household Panel (SHP); car registration data, aggregated to the municipal and cantonal level, were provided by the Federal Roads Office; and information on average incomes and income inequality, again for each municipality and canton, originate from the Swiss Federal Tax Administration. Unfortunately, the years for which the data are available do not exactly match. Car 
registrations are available for the years 2001 and 2007, whereas income inequality data are available for the years 2003 and 2006. The mismatch is kept at a minimum (plus or minus one year) by choosing 2002 and 2007 as base years and extracting the corresponding person-year observations from the SHP.

The SHP is comparable in structure and scope to other European panel household surveys, such as the German Socio-Economic Panel or the British Household Panel, now Understanding Society. It was started in 1999 and is ongoing at annual frequency (Budowski et al., 2001). Importantly, the Swiss Household Panel collects information on the following question: In general, how satisfied are you with your life if 0 means "not at all satisfied" and 10 means "completely satisfied"? In addition, there are questions on satisfaction with a number of life domains, including satisfaction with income. The SHP also provides information on many of the control variables typically used in satisfaction regressions. These include household income, household size, age, marital status, employment status, and gender. Depending on year, there are between 4000 and 5000 person observations with complete information on the relevant variables.

An innovation of this paper is the augmentation of the SHP data with regional information on cars, mean incomes and income inequality. Two levels of regional aggregation are considered, the municipality and the canton. Switzerland is composed of about 2,900 municipalities. According to the population census of 2000, they range in size from 24 inhabitants (Corippo in the Verzasca Vally in Ticino) to 368,875 inhabitants (Zurich). A total of 1,053 municipalities are represented among participants of the Swiss Household Panel. Switzerland is a confederation of 26 cantons whose role and political functions closely resemble that of the States within the U.S.; Again, population sizes vary considerably, from a mere 15,199 
in the canton of Appenzell Innerrhoden to 1.3 million in the canton of Zurich.

------ Figure 2 about here -------

Exposure to conspicuous car consumption is defined by the number of newly registered Ferrari and Porsche cars per year per 1000 population in the municipality or canton the individual resides in $2^{2}$ We refer to this number from now on as "FP-ratio". In 2001, the FP-ratio varied between 0 and 7 at the municipal level and between 0.09 (canton of Berne) and 0.65 (canton of Zug) at the cantonal level (See Figure 2) $!^{3}$ Over the whole of Switzerland, a total of 1,459 Ferrari and Porsche cars was newly registered during the year 2001, corresponding to an FP-ratio of about 0.20 per 1000 population.

By 2007, the nationwide number of new registrations of Ferraris and Porsches had increased substantially. The "least conspicuous" canton (with a rate of 0.08 ) was now the canton of Glarus. In Zug, again the canton with by far the highest density of such new sport cars, the number had almost doubled to 1.27. It has to be pointed out that the number of newly registered cars may not be the best measure for conspicuous car consumption, as it measures the flow rather than the stock of such cars. Unfortunately, stock data are not kept on file by the Federal Roads Office. In the steady state, the stock is proportional to the flow.

Income inequality data stem from the Swiss Federal Tax Administration (Jeitziner and Peters, 2007). The SFTA publishes Gini coefficients for all municipalities and cantons of

\footnotetext{
${ }^{2} \mathrm{~A}$ third brand of some importance in the class of luxury sport cars, Maserati, was excluded because funding constraints precluded the acquisition of this additional data series.

${ }^{3}$ The 26 cantons of Switzerland are Zurich (zh); Bern (be); Lucerne (lu); Uri (ur); Schwyz (sz); Obwalden (ow); Nidwalden (nw); Glarus (gl); Zug (zg); Fribourg (fr); Solothurn (so); Basel-City (bs); Basel-Country (bl); Schaffhausen (sh); Appenzell Ausserhoden (ar); Appenzell Innerrhoden (ai); St. Gall (sg); Grisons (gr); Argovia (ag); Thurgau (tg); Ticino (to); Vaud (vd); Valais (vs); Neuchatel (ne); Geneva (ge); Jura (ju).
} 
Switzerland, as well as mean income, median income and number of people living in every municipality, for selected tax years. Every Swiss resident with income has to file an annual tax return. Taxable income includes income from all sources (mainly labor earnings, interest and rental income) but excludes social security contributions (retirement and unemployment insurance). The income of jointly declaring couples is divided evenly. The resulting Gini coefficient measures personal income inequality before taxes. This is not ideal, since utility is usually derived from disposable income, and many of the channels discussed in the previous section (including reference incomes, altruism and uncertainty) are more appropriately thought of in terms of post-tax income. However, pre- and post-tax Gini coefficients are highly correlated $4^{4}$

The final sample is restricted to survey participants aged between 20 and 70 who provided valid information for all left- and right-hand side variables in both 2002 and 2007. Since all regression specifications include individual specific fixed effects, only persons with two years of data contribute to the estimation, and all others can be disregarded. Table 1 shows the descriptive statistics for these 4048 observations.

\section{------ Table 1 about here -------}

We see that mean income satisfaction decreased between 2002 and 2007 from 7.31 to 7.19 on the $0-10$ scale while average life satisfaction decreased from 8.00 to 7.89 . These changes

\footnotetext{
${ }^{4}$ For example, Feld et al. (2010, Table A2) report a standard deviation for the difference of pre- and post-tax Gini coefficients at the cantonal level of 0.21 , which, given the respective standard deviations of 2.53 and 2.34 of pre- and post-tax Ginis, implies a correlation of 0.99 .
} 
are statistically significant:5 Among the potential contributing factors, the increase in the FP-ratio - from 0.24 to 0.31 at the municipal level, and from 0.24 to 0.33 at the canton level - is the most "conspicuous", apart from the fact that all respondents are by construction five years older by the time of the second response. Inequality at the canton level also increased somewhat, as did average income. Whether the correlation between mean satisfaction and the FP-ratio over time is just that, a correlation, or else an effect with a plausibly causal interpretation, will be investigated in the next section by means of an extended regression analysis.

\section{Empirical Models and Results}

The effect of conspicuous consumption on satisfaction is estimated by exploiting variation in the density of Ferraris and Porsches across region and time. Are those who live in a municipality or canton with relatively more such luxury cars less satisfied than others, and if so, how large is the effect of conspicuous consumption on well-being? We would like to estimate the effect "all else equal", and therefore use regression analysis to account for potential confounders. Among them, income is perhaps the most important variable to include, since it is, first, a proxy for own consumption, and, second, a natural monetary comparison scale in order to gauge the magnitude of the consumption externality. Income is defined as annual disposable household income, i.e., net of taxes and including all transfers.

Other controls are the usual individual socio-demographic variables, an income comparison term (an indicator variable that takes the value 'one' if own income is above mean

\footnotetext{
${ }^{5}$ Note that the two samples are not independent, as they represent repeated measurements on the same individuals and substantial positive within-person correlation is to be expected. The standard error of the average change in income satisfaction is 0.043 , which leads to a $t$-statistic of -2.7 .
} 
regional income, and the value 'zero' else), and finally individual and region specific fixed effects. A balanced panel is used, with 2024 person-observations in either year. The models are estimated with and without controlling for the regional income Gini coefficient. It is clear that income inequality and conspicuous consumption are closely related. People might have negative feelings about income inequality per se (Alesina et al., 2004, Winkelmann and Winkelmann, 2010). Without controlling for income inequality, it is hard to say whether the effect of FP-ratio captures genuine conspicuous consumption, or inequality aversion more broadly. By controlling for income inequality, the specific consumption externality can be isolated in principle. The question is then whether, for a given level of inequality, people's income and life satisfaction depends on the way the money is spent by those in the upper parts of the income distribution, namely more or less conspicuously.

Table 2 displays results for the municipality based analysis, Table 3 the results for the canton based analysis. There are two sets of two regressions (with and without control for the Gini, respectively), the first set for income satisfaction as dependent variable and the second set for overall life satisfaction. Life satisfaction is often conceptualized as an aggregation of various domain satisfactions, the income domain being one of them (e.g., van Praag and Ferrer-i-Carbonell, 2004). Since largely unobserved variation in all the different domains feed into overall life satisfaction, we would expect that the income satisfaction models have more explanatory power than the life satisfaction models.

\section{------ Table 2 about here ------}

Table 2 shows the estimated coefficients. Household income has a statistically significant effect on both income and life satisfaction. A 10 percent increase in household income is predicted to increase income satisfaction by 0.055 points, or .7 percent if evaluated at the mean income satisfaction of 7.2. For life satisfaction, the effect is about half as large. It 
is customary in this literature to find statistically significant but economically rather small income elasticities, regardless of whether income satisfaction or life satisfaction is used as dependent variable.

The key parameter of interest is the estimated coefficient of the FP-ratio variable. In the model with income satisfaction as dependent variable, the point estimate is -0.15 . The effect is statistically significant at the $10 \%$ level. The magnitude and statistical significance of the estimate is unaffected by the inclusion of the Gini coefficient as an additional control variable. Thus, one additional Ferrari or Porsche per thousand population (or 17 additional cars for the municipality size of the average person in the sample) is predicted to lower income satisfaction by about the same amount as a $.015 / 0.55=27 \%$ reduction in household income. One additional car represents about the difference between the least conspicuous and the most conspicuous canton in 2007. For an alternative perspective, take the 2001 figure of 0.20 Ferraris and Porsches per thousand inhabitants in Switzerland. According to the estimates in Table 2, doubling that rate would have an adverse effect on predicted income satisfaction equal to that of a 5 percent reduction in income.

While the estimated conspicuous consumption parameter is negative in the life satisfaction equations as well, it is substantially smaller and no longer statistically significant. Substantial statistically uncertainty is also present for the other regression parameters, including those capturing the effects of relative income and household size. This is in part a reflection of the study design: controlling for individual specific effects is important to guard against bias from omitted time-invariant confounders and different anchoring of the subjective response scales across individuals. With two years of data, it also cuts the degrees of freedom by half, and it eliminates from the estimation sample all persons that are observed for a single year only. The remaining sample of 2048 persons is rather small. Since 
regional effects are included as well, the amount of available information is further reduced 6 Given these limitations, it is even more remarkable that a statistically significant effect of the municipal FP-ratio on income satisfaction can be found.

In a next step, the analysis is repeated for a different level of spatial aggregation, the canton level. It is a-priori unclear, in what direction one would expect the results to move, as there are a number of opposing forces. For example, there is less variation of the FP-ratio between cantons than between municipalities and and the precision of the estimates can be expected to go down as a conseqence. On the other hand, since the number of new carregistrations is used as a proxy for the stock of such cars, the measurement error will tend to be lower for larger geographic units than for smaller ones (where there is a substantial fraction of municipalities with zero new registrations in a given year). From a substantial point of view, the spatial dimension of the consumption externality remains ambiguous. In the cantons, which are the bigger units, inhabitants in the different parts of the units are unlikely to know of, and respond to, the behavior of each other. While it is obviously the case that cars are used to drive around, inside and outside the canton, it is also arguably the case that the exposure to such consumption externalities is the greatest at the local level, and most so in the immediate neighborhood.

\section{------ Table 3 about here -------}

Table 3 shows the regression results for the analysis at the cantonal level. The regressions models and estimation samples are identical to those used for Table 2, except that the FPratio and Gini coefficient are measured at the level of the canton, and that canton rather than municipality specific fixed effects are included in addition to the individual specific fixed effects. It turns out that the FP-ratio point estimates effects are actually larger than before,

\footnotetext{
${ }^{6}$ The regional effects are identified from movers.
} 
in absolute value, in particular in the life satisfaction equations. However, standard errors have grown much so that none of the negative point estimates is statistically significant.

\section{Conclusions}

The first objective of this paper was to explore the life satisfaction approach as a conceptual framework for thinking about conspicuous consumption and consumption externalities. The traditional tools of welfare analysis identify externalities from behavioral responses. This limits the scope of questions one can answer. It is for example difficult to quantify the welfare loss resulting from envy, or to quantify the disutility of an externality, or the utility of a public good, more broadly. To value such intangibles, the satisfaction approach offers a potential alternative.

The second objective was to conduct a substantive empirical analysis for Switzerland and to determine the welfare costs of luxury sport cars. The results indicated that people living in a municipality with a higher prevalence of luxury cars have indeed a lower income satisfaction than others, ceteris paribus. Doubling the number of Ferraris and Porsche at the national average is estimated to have an adverse effect on mean income satisfaction that equals that of a 5 percent reduction in income. The results for life satisfaction and cantonal spillovers were inconclusive, although negative point estimates were found as well.

Of course, areas with many Ferraris and Porsches are also likely to have more buyers of other expensive cars, and a higher incidence of other displays of wealth (such as luxury condominiums). Without explicitly controlling for these factors, the Ferrari and Porsche density can best be interpreted as a proxy for the overall amount of conspicuous consumption that is taking place. The basic assumption is that the more Ferraris and Porsches there are in a municipality or canton, the higher the incidence of conspicuous consumption, whatever its 
specific manifestation. The effects should thus not be interpreted as ceteris paribus (keeping other forms of such conspicuous consumption constant) but rather mutatis mutandis.

Future work in this area should aim at improving statistical power. In order to obtain more precise estimates and make further progress on the issue, one might use more data of the same kind. For example, purchasing additional car registration data would allow extending the analysis to other years. Or else, one might look for related but different data. In 2009, an "initiative for human friendly cars" was successful in collecting a sufficient number of signatures, so that a referendum proposing restrictions on the type of cars sold as well as additional luxury taxes for certain classes of vehicles must be put to the people in Switzerland in due course. Once available, such voting results can be used to confirm whether the proposed policy measures find more support in regions where the consumption externalities are objectively more present. 


\section{References}

Alesina, A., R. Di Tella and R. MacCulloch (2004) Inequality and happiness: are Europeans and Americans different? Journal of Public Economics 88, 2009-2042.

Arrow, K.J. and P.S. Dasgupta (2009) Conspicuous Consumption, Inconspicuous Leisure, Economic Journal 119: F497-F516.

Budowski,M., R. Tillmann, E. Zimmermann, B. Wernli, A. Scherpenzeel and A. Gabadinho (2001). The Swiss Household Panel 1999-2003: Data for research on microsocial change, ZUMA-Nachrichten. 50: 100-125.

Charles, K.K., E. Hurst and N. Roussanov (2009) Conspicuous Consumption and Race, Quarterly Journal of Economics, 124, 425-467.

Clark, A.E. and A.J. Oswald (1996) Satisfaction and comparison income, Journal of Public Economics, 61, 359-381.

Di Tella, R., J. Haisken-De New and R. MacCulloch (2007) Happiness Adaptation to Income and to Status in an Individual Panel, NBER Working Papers 13159.

Dupor, B., and W.-F. Liu (2003) Jealousy and Equilibrium Overconsumption, American Economic Review, 93, 423-428.

Dynan, K.E., and E. Ravina (2007) Increasing Income Inequality, External Habits, and Self-Reported Happiness, American Economic Review, 97, 226-231.

Easterlin, Richard A. (1974) Does Economic Growth Improve the Human Lot? Some Empirical Evidence. In Nations and Households in Economic Growth: Essays in Honor of Moses Abramovitz, ed. Paul A. David and Melvin W. Reder. New York: Academic Press, 89-125. 
Feld, L.P., J. Fischer and G. Kirchgässner (2010) The effect of direct democracy on income redistribution: evidence for Switzerland, Economic Inquiry, 48, 817-840.

Frank, R.H. (1991) Positional externalities, In: Zeckhauser, R.J. (Ed.), Strategy and Choice, MIT Press, Cambridge, MA, 25-47.

Frank, R. (1999) Luxury fever: Why money fails to satisfy in an era of excess. New York: Free Press.

Frank, R. (2004) How not to buy happiness, Deadalus, 133(2), 69-79.

Frey, B.S., S. Luechinger and A. Stutzer (2009) The life satisfaction approach to valuing public goods: The case of terrorism, Public Choice, 138, 317-345.

Heffetz, O. (2011) A Test of Conspicuous Consumption: Visibility and Income Elasticities, Review of Economics and Statistics, forthcoming.

Hsee, C.K., F. Xu and N. Tang (2008) Two Recommendations on the Pursuit of Happiness, Journal of Legal Studies, 37, S115- S132.

Jeitziner, B. and R. Peters (2007) Regionale Einkommens- und Vermögensverteilung in der Schweiz: Was sagen die Steuerdaten? Die Volkswirtschaft, issue 12.

Johansson-Stenman, O. and P. Martinsson (2006) Honestly, why are you driving a BMW? Journal of Economic Behavior \& Organization, 60, 129-146.

Kahneman, D. and R.H. Thaler (1991) Economic Analysis and the Psychology of Utility: Applications to Compensation Policy, American Economic Review, 81, 341-346.

Krueger, A.B. and D.A. Schkade (2008) The Reliability of Subjective Well-Being Measures, Journal of Public Economics, 92, 1833-1845. 
Kuhn, P., P. Kooreman, A.R. Soetevent and A. Kapteyn (2011) The Effects of Lottery Prizes on Winners and their Neighbors: Evidence from the Dutch Postcode Lottery, forthcoming in: American Economic Review.

Layard, R. (1980) Human Satisfactions and Public Policy, Economic Journal, 90, 737-750.

Layard, R. (2005) Happiness - Lessons from a New Science, Penguin Press, New York.

Luechinger, S. (2009) Valuing Air Quality Using the Life Satisfaction Approach, Economic Journal, 119, 482-515.

Luttmer, E.F.P. (2005) Neighbors as negatives: relative earnings and well being, Quarterly Journal of Economics, 120, 963-1002.

Marmot, M. (2003) Understanding Social Inequalities in Health, Perspectives in Biology and Medicine 46, S9-S23.

Marx, K. (1987[1847]) Wage, Labour and Capital.

Neumark, D. and A. Postelwaite (1998) Relative income concerns and the rise in married women's employment, Journal of Public Economics, 70, 157-193.

Oswald, A.J. and M.D. Rablen (2008) Mortality and Immortality: The Nobel Prize as an Experiment into the Effect of Status upon Longevity, Journal of Health Economics, $27,1462-1471$.

SFSO (2005) Eidgenössische Volkszählung 2000: Die Raumgliederung der Schweiz, Neuenburg: Swiss Federal Statistical Office.

Solnick, S. and D. Hemenway (1998) Is more always better?: a survey on positional concerns. Journal of Economic Behavior and Organization, 37, 373-383. 
Stutzer A. and B.S. Frey (2008) Stress that Doesn't Pay: The Commuting Paradox, Scandinavian Journal of Economics, 110, 339-366.

van Praag, B.M.S. and B.E. Baarsma (2005) Using Happiness Surveys to Value Intangibles: The Case of Airport Noise, Economic Journal, 115, 224-246.

van Praag, B. and A. Ferrer-i-Carbonell (2004) Happiness Quantified - A Satisfaction Calculus Approach, Oxford University Press.

Veblen, T. (1925[1899]) The Theory of the Leisure Class: An Economic Study of Institutions.

Veenhoven, R. (2008) Healthy happiness: effects of happiness on physical health and the consequences for preventive health care, Journal of Happiness Studies, 9, 449-469.

Wilkinson, R. (2000) Mind the Gap: Hierarchies, Health and Human Evolution, Weidenfeld \& Nicolson, London.

Winkelmann L. and R. Winkelmann (2010) Does inequality harm the middle class? Kyklos, $63,301-316$. 
Table 1

Descriptive Statistics

\begin{tabular}{lcccc}
\hline \hline & \multicolumn{2}{c}{ Year 2002 } & \multicolumn{2}{c}{ Year 2007 } \\
& mean & std.err. & mean & std.err. \\
\hline & & & & \\
Income Satisfaction & 7.31 & $(0.041)$ & 7.19 & $(0.044)$ \\
Life Satisfaction & 8.00 & $(0.031)$ & 7.89 & $(0.030)$ \\
Household size & 3.08 & $(0.032)$ & 2.93 & $(0.031)$ \\
Log household income & 10.88 & $(0.011)$ & 10.98 & $(0.011)$ \\
Married (Yes=1) & 0.70 & $(0.010)$ & 0.71 & $(0.010)$ \\
Ferrari\&Porsche/1000 pop. (munic.) & 0.24 & $(0.008)$ & 0.31 & $(0.016)$ \\
Ferrari\&Porsche/1000 pop. (canton) & 0.24 & $(0.002)$ & 0.33 & $(0.005)$ \\
Gini (munic.) & 0.29 & $(0.001)$ & 0.29 & $(0.001)$ \\
Gini (canton) & 0.30 & $(0.001)$ & 0.32 & $(0.001)$ \\
Log Mean income (munic.) & 10.84 & $(0.004)$ & 10.89 & $(0.004)$ \\
Log Mean income (canton) & 10.86 & $(0.002)$ & 10.91 & $(0.003)$ \\
& & & & \\
Number of observations & 2024 & & 2024 & \\
\hline
\end{tabular}


Fig. 1. Index of New Car Registrations in Switzerland $(2000=100)$
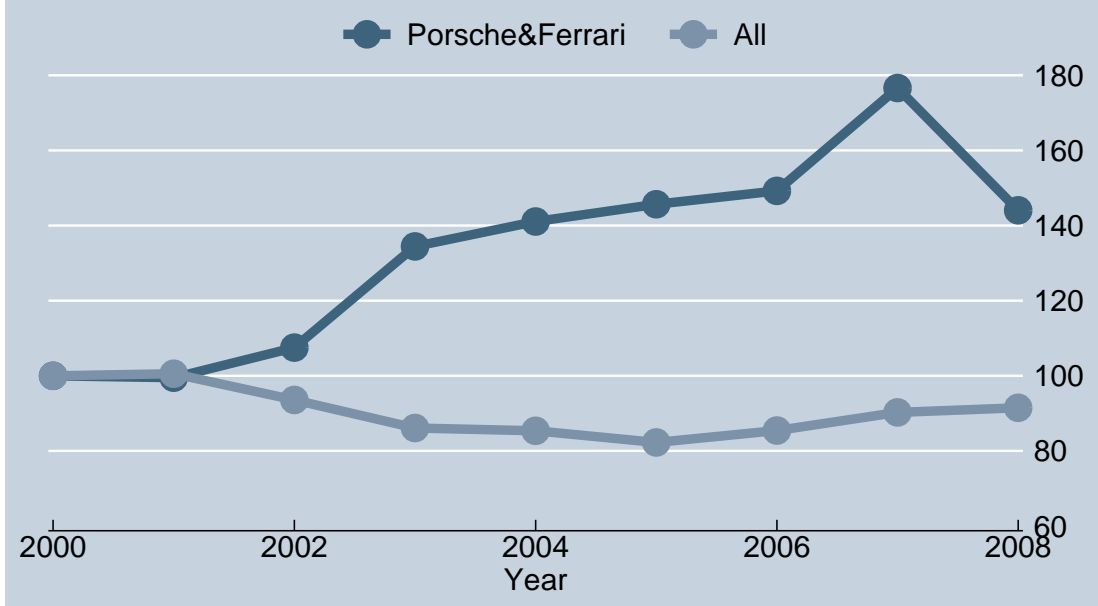

Source: www.auto-schweiz.ch

Fig. 2. Cantonal ranking in luxury car registrations per 1000 pop., 2001

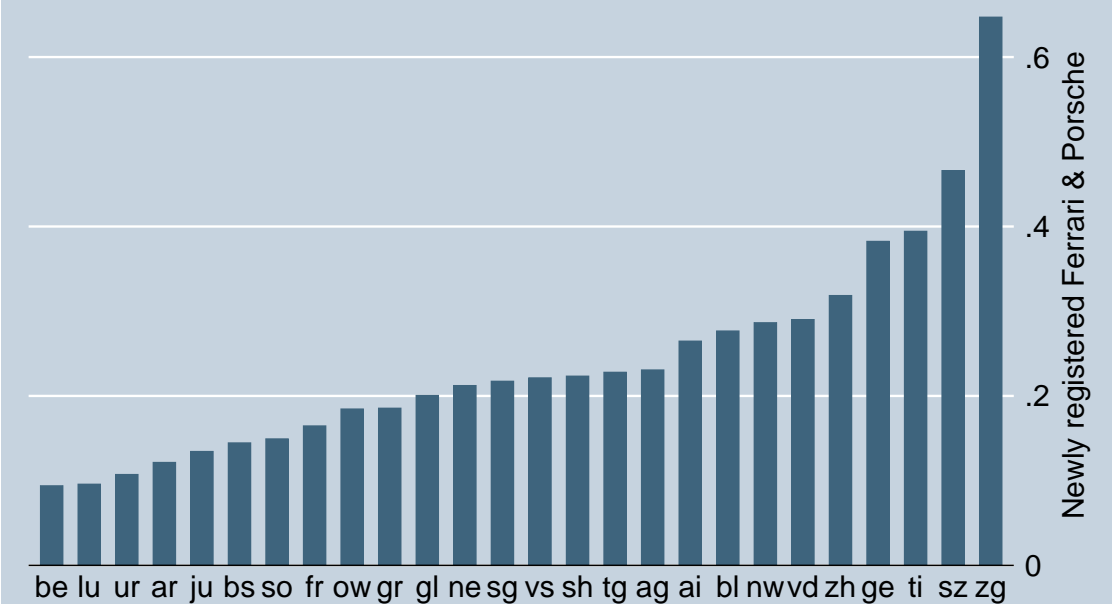

Source: Federal Roads Office, own calculations. 
Table 2

Satisfaction, Inequality and Luxury Cars in Municipality

\begin{tabular}{|c|c|c|c|c|}
\hline \multirow[b]{2}{*}{ Log household income } & \multicolumn{2}{|c|}{ Income Satisfaction } & \multicolumn{2}{|c|}{ Life Satisfaction } \\
\hline & $\begin{array}{c}0.546^{* *} \\
(0.142)\end{array}$ & $\begin{array}{c}0.548^{* *} \\
(0.142)\end{array}$ & $\begin{array}{c}0.287^{* *} \\
(0.105)\end{array}$ & $\begin{array}{c}0.285^{* *} \\
(0.105)\end{array}$ \\
\hline Income above municipal mean & $\begin{array}{c}0.129 \\
(0.116)\end{array}$ & $\begin{array}{c}0.127 \\
(0.116)\end{array}$ & $\begin{array}{c}0.035 \\
(0.086)\end{array}$ & $\begin{array}{c}0.036 \\
(0.086)\end{array}$ \\
\hline Ferrari\&Porsche/1000 pop. & $\begin{array}{c}-0.150^{*} \\
(0.082)\end{array}$ & $\begin{array}{c}-0.147^{*} \\
(0.082)\end{array}$ & $\begin{array}{l}-0.045 \\
(0.061)\end{array}$ & $\begin{array}{c}-0.047 \\
(0.061)\end{array}$ \\
\hline Municipal Gini & & $\begin{array}{l}-0.015 \\
(0.024)\end{array}$ & & $\begin{array}{c}0.012 \\
(0.018)\end{array}$ \\
\hline Log household size & $\begin{array}{c}0.118 \\
(0.177)\end{array}$ & $\begin{array}{c}0.115 \\
(0.177)\end{array}$ & $\begin{array}{c}0.024 \\
(0.131)\end{array}$ & $\begin{array}{c}0.026 \\
(0.131)\end{array}$ \\
\hline R-squared & 0.220 & 0.221 & 0.162 & 0.162 \\
\hline Individual fixed effects & yes & yes & yes & yes \\
\hline Municipality fixed effects & yes & yes & yes & yes \\
\hline
\end{tabular}

Notes:

Number of observations: 4048; Source: Swiss Household Panel; Other control variables not shown in table are a second order polynomial in age, marital status, and unemployment; standard errors in parentheses; * $\mathrm{p}<0.10,{ }^{* *} \mathrm{p}<0.05$ 
Table 3

Satisfaction, Inequality and Luxury Cars in Canton

\begin{tabular}{|c|c|c|c|c|}
\hline \multirow[b]{2}{*}{ Log household income } & \multicolumn{2}{|c|}{ Income Satisfaction } & \multicolumn{2}{|c|}{ Life Satisfaction } \\
\hline & $\begin{array}{c}0.326^{* *} \\
(0.127)\end{array}$ & $\begin{array}{c}0.318 * * \\
(0.127)\end{array}$ & $\begin{array}{c}0.242^{* *} \\
(0.092)\end{array}$ & $\begin{array}{c}0.247^{* *} \\
(0.092)\end{array}$ \\
\hline Income above canton mean & $\begin{array}{c}0.320^{* *} \\
(0.106)\end{array}$ & $\begin{array}{c}0.327^{* *} \\
(0.106)\end{array}$ & $\begin{array}{l}-0.020 \\
(0.077)\end{array}$ & $\begin{array}{l}-0.024 \\
(0.077)\end{array}$ \\
\hline Ferrari\&Porsche/1000 pop. & $\begin{array}{l}-0.310 \\
(0.343)\end{array}$ & $\begin{array}{l}-0.046 \\
(0.385)\end{array}$ & $\begin{array}{l}-0.140 \\
(0.248)\end{array}$ & $\begin{array}{l}-0.294 \\
(0.278)\end{array}$ \\
\hline Cantonal Gini & & $\begin{array}{l}-0.049 \\
(0.032)\end{array}$ & & $\begin{array}{c}0.028 \\
(0.023)\end{array}$ \\
\hline Log household size & $\begin{array}{c}0.072 \\
(0.136)\end{array}$ & $\begin{array}{c}0.073 \\
(0.136)\end{array}$ & $\begin{array}{c}0.055 \\
(0.098)\end{array}$ & $\begin{array}{c}0.054 \\
(0.098)\end{array}$ \\
\hline R-squared & 0.050 & 0.051 & 0.029 & 0.029 \\
\hline Individual fixed effects & yes & yes & yes & yes \\
\hline Canton fixed effects & yes & yes & yes & yes \\
\hline
\end{tabular}

Notes: see Table 2. 